\title{
THE USE OF E-SUPERVISION TO SUPPORT SPEECH-LANGUAGE PATHOLOGY GRADUATE STUDENTS DURING STUDENT TEACHING PRACTICA
}

\author{
Charles H. CARlin, PH.D., CCC-SlP, Katie BOARMAN, M.A., CCC-SlP, \\ EMILY CARLIN, M.A., CCC-SLP, KARISSA INSELMANN, B.S. \\ THE UNIVERSITY OF AKRON, AKRON, OHIO, USA
}

\section{ABSTRACT}

In the present feasibility study, e-supervision was used to provide university liaison supervision to speech-language pathology (SLP) graduate students enrolled in student teaching practica. Utilizing a mixed methodology approach, interview and survey data were compared in order to identify similarities and differences between in-person and e-supervision, and guide future practice. Results showed e-supervised graduate students perceived that they received adequate supervision, feedback, support, and communication. Further, e-supervision provided additional benefits to supervisors, children on the caseload, and universities. Despite the benefits, disadvantages emerged. Implications for future practice and limitations of the study were identified.

Keywords: e-supervision, university liaison supervision, speech-language pathologist, student teaching

Graduate students in speech-language pathology programs are often required to complete student teaching practica in school districts as part of state licensure and graduation requirements. During student teaching practica, a graduate student is paired with a cooperating school-based speech-language pathologist (SLP) from that district who provides direct supervision over the course of an extended period of time (i.e., quarter, semester). Additionally, the graduate student is assigned a university liaison supervisor (ULS) who travels to the school district for supervision purposes. The ULS bridges the gap between what is taught at the university and what is occurring at the school, what the graduate student believes and what the cooperating school SLP supervisor thinks is best practice, and what the graduate student wants to learn and what needs to be learned according to the university and licensure standards (Yusko, 2004).

Shortages of cooperating school-based SLP supervisors limit the availability of high-quality student teaching placements (ASHA, 2008), and in turn prevent graduate students from meeting the practicum requirements for state and national licensure (ASHA, 2007; Dudding \& Justice, 2004). In addition to a limited number of cooperating school-based SLP supervisors, universities also experience difficulty locating a ULS who is qualified and able to travel to the school district. Without a qualified ULS, the graduate student experiences disconnect between content learned at the university and school district levels.
While shortages of ULSs impact the quality of supervision graduate students receive, heavy workloads also decrease the amount of time available for supervision. Further, onsite travel to student teaching sites can be time consuming, especially if graduate students are placed in rural settings (Carlin, Milam, Carlin, \& Owen, 2012). ULSs often supervise more than one graduate student and therefore, time in the work day must be set aside for travel. As more students are assigned to ULSs, more time must be devoted to travel, which results in less time to complete other university responsibilities (Olson, Russell, \& White, 2001). Additionally, even if appropriate ULSs are located, scheduling conflicts arise during the student teaching experience. This is especially true when school districts close, graduate students become ill, and children do not show up to speech-language services.

In an effort to combat ULS shortages, busy work schedules, increased travel time, and scheduling conflicts, graduate programs sometimes assign retired teachers or school administrators to be ULSs. Although these teacher and administrator supervisors possess a wealth of school-based experiences and reside near the school, they are not SLPs and do not possess necessary speech-language pathology content knowledge.

Moreover, these individuals lack the ability to support the attainment of speech-language clinical competencies. 


\section{ADDRESSING BARRIERS THROUGH TECHNOLOGY}

Speech-language pathology graduate programs are encouraged to use desktop videoconferencing programs and other technologies to address challenges related to supervisor shortages (Carlin et al., 2012; Hallett, 2002; Robinson, Creaghead, Hooper, Watson, \& McNeilly, 2007). E-supervision provides a technological solution and allows universities to hire qualified individuals to supervise during student teaching practica (Dudding, 2009). E-supervision, also known as tele- or distance supervision, is a model that uses two-way audio and videoconferencing technology to provide real-time clinical supervision (Carlin, Carlin, Milam, \& Weinberg, 2013). E-supervisors are housed in centralized locations (e.g., university office, home) and do not travel to student teaching sites. E-supervisors use videoconferencing technology to observe and evaluate the performance of supervisees in real-time during direct diagnostic, therapeutic, and consultative activities that occur in the pullout therapy room, classroom, or other school settings (Carlin et al., 2013). Additionally, this model allows synchronous verbal communication or instant messaging between the supervisor and graduate student (Carlin et al., 2012).

According to Dudding and Justice (2004), the use of two-way videoconferencing is a viable, practical, and cost-effective method to supervise graduate students in hard-to-fill, remote, rural, and underserved public school districts. The cost of the e-supervision technology is offset by the increase in clinical supervision, decrease in travel time and related costs, and flexibility in scheduling (Dudding \& Justice, 2004). Further, e-supervision meets the needs of faculty members who do not have the ability or time to provide in-person supervision to graduate students placed off campus (Olson, Russell, \& White, 2001).

\section{E-SUPERVISION PROCEDURES}

In order to address shortages of qualified ULSs, reduce supervisory related travel costs, and free up supervisors' time, The University of Akron School of Speech Language Pathology and College of Education collaborated on an e-supervision feasibility study. The study was funded by The University of Akron, and lasted from February through April 2011. Graduate SLP students enrolled in student teaching practica were assigned to a school district based upon their interests and places of residence. While placed at their student teaching site, graduate students received daily in-person supervision from cooperating SLP supervisors. Additionally, a ULS was assigned to each student, and the delivery of supervision varied depending on the supervisor's ability to drive to the school district. If a ULS was unable to travel to the student teaching site, e-supervision was provided. Given the remoteness of some student teaching sites, three e-supervisors were used in this study. Two supervisors had over 18 years of experience supervising graduate students at the university level and both previously worked as schoolbased SLPs. The third supervisor had 5 years of clinical supervision experience and worked as a school-based SLP.

At the start of the semester, each graduate student and university liaison e-supervisor (ULE-S) were loaned equipment for use during the study. They received a Logitech Quick Cam Orbit AF webcam, Logitech USB Desktop Microphone, and a Dell PS511 USB Internal Speaker. Videoconferencing technology was downloaded onto cooperating SLPs' school district computers and the ULE-Ss' university provided Dell laptops.

According to College of Education policy, each ULE-S was expected to observe a graduate student 4-5 times during a semester and conduct at least two follow-up meetings with the student and cooperating SLP supervisor. Graduate student and ULE-S pairs scheduled mutually convenient times to hold observations and follow-up teleconferences. Graduate students were primarily observed during one-on-one or small group pullout speech-language therapy and sessions were not recorded. After the session ended or at a later date, ULESs held tele- or videoconferences with the cooperating school SLPs and graduate students. At these meetings, ULE-Ss discussed observation data, completed problemsolving activities, set goals for future observations, and provided suggestions for improvement. In addition, written feedback and resource materials were provided.

\section{PURPOSE OF THE STUDY}

The study was designed to be a cost-effective and an efficient means to provide high-quality university liaison e-supervision to SLP graduate students placed in rural and remote school districts during student teaching. Three questions guided this study. First, how do ULE-Ss support graduate students enrolled in student teaching? Second, what are the similarities and differences between graduate students' perceptions of in-person supervision and e-supervision? And finally, how can universities and cooperating school districts effectively implement university liaison e-supervision? 


\section{METHOD}

The study employed a mixed methodology approach, in which surveys and interviews were used to explore answers to the three research questions. This approach allowed a full variety of data to be collected and a richer understanding of the results (Johnson, Onwuegbuzie, \& Turner, 2007). The mixed methodology approach further enabled the researchers to analyze data sets for trends, themes, and emergent ideas (Carlin et al., 2012). Finally, data were triangulated to better illustrate trends and support emerging clinical implications (Flick, 2004).

\section{DATA COLLECTION AND ANALYSis}

The survey instrument used, The Survey of University Liaison Supervisor, was developed by the Office of Student Teaching at The University of Akron. The survey was designed to measure graduate students' perceptions of their experiences with ULSs. Items on the survey asked for the students' level of program (i.e., graduate or undergraduate), licensure program (e.g., speech pathology), and name of the ULS. As can be seen in Table 1, graduate students were asked to respond to 15 questions on the survey by checking "a great deal"; "a moderate amount"; or "little or not at all." Survey questions were divided into five distinct categories: supervisory interactions, diversity of thought and instructional practices, technology use, ethical practice, and educationally sound decisions. Graduate students completed a paper-pencil version of the survey at a class meeting near the conclusion of their student teaching practica.

In addition to survey data, graduate students participated in one-on-one semi-structured interviews about their perceptions of and experiences with university liaison in-person and e-supervision. Graduate students were interviewed individually by the lead researcher or a trained research assistant using a series of eight interview questions (Carlin et al., 2012). The interview responses were recorded and transcribed by the lead researcher; the questions can be found in the appendix. All interviews occurred after students' grades were finalized and posted. The interview transcripts were coded and organized by themes and trends.

Reoccurring patterns across the data were identified (Merriam, 1998) and comparisons were made between the two types of supervision (i.e., in-person and e-supervision). When the survey and interview data were taken as a whole, a better understanding of the graduate students' perceptions of e-supervision emerged. Additionally, data sets permitted the researchers to identify how e-supervision supported graduate students and how it could be used during future e-supervision projects.

\section{PARTICIPANTS}

The 13 participants in the study were all second year graduate students enrolled in a speech-language pathology program. As part of their graduation requirement, graduate students were required to participate in a six semester hour student teaching practicum experience. Nine of the graduate students received in-person supervision and four received e-supervision.

A total of 13 surveys were administered at the end of the semester with a response rate of $100 \%$. From these students, four graduate students were purposively selected to participate in the interviews. They were selected because their placements were in public school districts, their student teaching caseloads were representative of a typical SLP caseload, and they were supervised by different faculty members. Two of the interviewed graduate students received in-person supervision and two received e-supervision. All four students consented and participated fully during the interviews.

\section{RESULTS}

In general, graduate students held positive perceptions about e-supervision. When comparing the results of the two supervision methods, data suggested the benefits of e-supervision were highly comparable to those associated with in-person supervision. Moreover, it may be presumed through the responses that the benefits of e-supervision outweighed those of in-person supervision in some instances.

The survey results are illustrated in Table 1. The response frequencies for the 15 perception questions were broken down into three categories of responses: Combined methods of supervision, e-supervision, and inperson supervision. The percentages were rounded to the nearest whole number. 
Table 1. Perception Questions on University Liaison Supervision

\begin{tabular}{|c|c|c|c|c|}
\hline \multirow{2}{*}{$\begin{array}{l}\text { Perception Statements } \\
\text { To what extent did your university supervisor: }\end{array}$} & \multirow[b]{2}{*}{$\begin{array}{l}\text { Supervision Type } \\
n=\text { sample size }\end{array}$} & \multicolumn{3}{|c|}{ \% Responding } \\
\hline & & A Great Deal & $\begin{array}{l}\text { A Moderate } \\
\text { Amount }\end{array}$ & $\begin{array}{l}\text { Little or } \\
\text { not at all }\end{array}$ \\
\hline \multirow{2}{*}{ 1. Assist you in reaching your learning goal? } & E-supervision $(n=4)$ & 50 & 50 & 0 \\
\hline & In-person $(n=9)$ & 44 & 33 & 22 \\
\hline \multirow{2}{*}{$\begin{array}{l}\text { 2. Provide you with specific feedback to improve } \\
\text { your therapy? }\end{array}$} & Combined & 77 & 15 & 8 \\
\hline & In-person $(n=9)$ & 67 & 22 & 11 \\
\hline \multirow{3}{*}{$\begin{array}{l}\text { 3. Facilitate communication between you } \\
\text { and the cooperating SLP? }\end{array}$} & Combined & 36 & 55 & 9 \\
\hline & E-supervision (n=2) & 0 & 50 & 50 \\
\hline & In-person $(n=9)$ & 44 & 56 & 0 \\
\hline 4. Demonstrate fairness? & Combined & 92 & 8 & 0 \\
\hline \multirow{2}{*}{$\begin{array}{l}\text { 5. Keep appointments and make him/herself } \\
\text { available for consultation/assistance? }\end{array}$} & E-supervision $(n=4)$ & 50 & 50 & 0 \\
\hline & In-person $(n=9)$ & 78 & 11 & 11 \\
\hline \multirow[t]{3}{*}{ 6. Prepare for consultation/assistance? } & Combined & 77 & 23 & 0 \\
\hline & E-supervision $(n=4)$ & 75 & 25 & 0 \\
\hline & In-person $(n=9)$ & 78 & 22 & 0 \\
\hline \multirow{3}{*}{$\begin{array}{l}\text { 7. Maintain high expectations for you } \\
\text { and the profession? }\end{array}$} & Combined & 92 & 8 & 0 \\
\hline & E-supervision ( $n=4)$ & 100 & 0 & 0 \\
\hline & In-person $(n=9)$ & 89 & 11 & 0 \\
\hline \multirow[t]{2}{*}{ 8. Guide and encourage reflective thinking? } & Combined & 77 & 15 & 8 \\
\hline & E-supervision $(n=4)$ & 75 & 25 & 0 \\
\hline \multirow{3}{*}{$\begin{array}{l}\text { 11. Encourage the use of technology for } \\
\text { instruction, assessment, and/or data analysis } \\
\text { to inform instructional practices? }\end{array}$} & Combined & 18 & 45 & 36 \\
\hline & E-supervision $(n=3)$ & 67 & 33 & 0 \\
\hline & In-person $(n=8)$ & 0 & 50 & 50 \\
\hline \multirow{3}{*}{$\begin{array}{l}\text { 12. Assist you in applying ethical standards } \\
\text { of the profession in your decision-making? }\end{array}$} & Combined & 45 & 36 & 18 \\
\hline & E-supervision ( $n=3)$ & 33 & 33 & 33 \\
\hline & In-person $(n=8)$ & 50 & 38 & 13 \\
\hline \multirow{3}{*}{$\begin{array}{l}\text { 13. Assist you in reflecting on your effectiveness } \\
\text { in helping all children learn? }\end{array}$} & Combined & 73 & 9 & 18 \\
\hline & E-supervision $(n=3)$ & 67 & 0 & 33 \\
\hline & In-person $(n=8)$ & 75 & 25 & 0 \\
\hline \multirow[t]{3}{*}{ 14. Model ethical behavior? } & Combined & 75 & 25 & 0 \\
\hline & E-supervision $(n=4)$ & 75 & 25 & 0 \\
\hline & In-person $(n=8)$ & 75 & 25 & 0 \\
\hline \multirow{3}{*}{$\begin{array}{l}\text { 15. Challenge you to make sure your decisions } \\
\text { were educationally sound? }\end{array}$} & Combined & 50 & 50 & 0 \\
\hline & E-supervision $(n=4)$ & 75 & 25 & 0 \\
\hline & In-person $(n=8)$ & 38 & 63 & 0 \\
\hline
\end{tabular}




\section{UNIVERSITY LIAISON SUPERVISION AND SUPERVISOR INTERACTIONS}

\section{SIMILARITIES}

According to survey and interview results, students who received in-person and e-supervision held many similar perceptions. During the interviews, in-person and e-supervised graduate students reported they were adequately supervised and able to collaborate on therapy ideas, gain additional clinical perspectives, and share feedback. Similarly, both groups of graduate students believed ULSs displayed a great deal of preparedness when providing consultation and assistance. Both in-person ULSs and ULE-Ss provided a great deal of assistance in helping students reflect on their effectiveness in helping all children learn. The two groups of graduate students agreed ULSs guided and encouraged a great deal of reflective thinking and demonstrated ethical behavior.

Graduate students from both groups were equally uncertain about the extent to which their respective ULSs assisted in the attainment of personal learning goals. During the interviews, graduate students did not feel ULSs were able to provide the same level of support as the cooperating SLP supervisor. As one student put it, "The only downside about that was [the ULS] was only able to see bits and pieces of how I was doing in therapy; [the ULS] didn't really see the long-term effects or the longterm progress."

\section{DIFFERENCES}

While several elements were similar between the two types of supervision, university liaison e-supervision was superior to in-person supervision in some respects. When compared to past in-person supervision experiences, graduate students felt e-supervision was less threatening and overwhelming. One graduate student felt e-supervision enabled her to "feel more independent" when providing speech-language services. Since the ULE-Ss were not physically present at the school district, graduate students also felt less distracted and intimidated because they could "turn the screen off and forget that [they] were being observed."

During certain instances, university liaison e-supervision afforded the graduate students more or better feedback when compared to in-person supervision. Recall that all ULE-Ss were SLPs with school-based experiences, and these supervisors provided a great deal of specific feedback and challenged graduate students a great deal to make educationally sound decisions. Additionally, e-supervised graduate students believed the ULE-S offered a great deal of feedback to improve therapy and differentiate instruction to meet the needs of all children on the caseload. A higher percentage of e-supervised graduate students believed ULE-Ss demonstrated a great deal of fairness and maintained high expectations for the students and the field of speech-language pathology.

Although ULE-Ss were perceived to offer better feedback at times, in-person ULSs were perceived as better able to assist students in reflecting on attitudes and opinions regarding diversity and applying ethical standards of the profession. Additionally, in-person ULSs were also better able to keep appointments and be available for consultation and assistance. The data were not clear as to why in-person ULSs were better in these areas.

Finally, the videoconferencing technology somewhat isolated the ULE-Ss from what occurred at the school site. None of the e-supervised graduate students believed the ULE-Ss facilitated a great deal of communication between the cooperating SLP supervisor and the graduate student. During the interviews, one e-supervised graduate student recalled how the ULE-S "never introduced herself" to the cooperating SLP supervisor, which then "negatively affected the rapport and working relationship" that existed. In addition to isolating the ULE-S from the cooperating SLP supervisor, the videoconferencing technology also impacted ULE-Ss' ability to "get to know the kids" on the caseload and offer guidance.

\section{INFLUENCE OF TECHNOLOGY ON THE SUPERVISION PROCESS}

\section{BENEFITS}

The use of technology during this study appeared to affect the supervisory process. More specifically, ULE-Ss tended to do a better job of encouraging the graduate students to use technology for instruction, assessment, and/or data analysis. During the interview, a graduate student shared how the videoconferencing technology and computer were used to provide visual feedback and reinforcement for a young boy with a speech sound disorder. The child was able to look at himself on the computer screen while imitating and independently producing target speech sounds.

In addition to being used for motivational and feedback purposes, the technology prevented small therapy rooms from being overly crowded and distracting. During e-supervision, children on the caseload were not affected by new or additional people in the room or added noises (i.e., rustling papers, moving chairs, typing notes). When in-person ULSs were used, their presence in the room caused the children to be distracted. One in-person supervised graduate student shared the following:

The kids were distracted a lot. They asked who the new person was so I had to explain why he was there, which cut into our therapy time. Then they kept looking at him instead of paying attention to me so I had to keep redirecting....One, the kids didn't get the best therapy they could have that day and two, it didn't show my full 
potential and how I can normally effectively manage the situation because they were distracted.

\section{LIMITATIONS}

While the technology was used to enhance services and prevented overcrowding and distractions, it nonetheless introduced certain limitations into the supervisory process. When therapy was conducted outside the therapy room (e.g., in a regular education classroom), ULE-Ss were not able to observe fully the moving graduate student or the entire physical space. The cooperating SLP supervisors' office desktop computers were not portable and classroom-based computers were not situated near each child on the caseload. Even when a laptop computer was used and the Internet was available, the ULE-Ss were not always able to hear the target child due to background noises in the general education setting. These issues limited where observations could occur, who could be observed, and how well children could be heard.

Not only did the technology limit ULE-Ss' ability to observe students outside of the therapy room, but school district Internet connections and policies also caused difficulties. Poor or no Internet connectivity emerged as the biggest limitation for e-supervised graduate students. ULE-Ss were not able to observe in settings that did not have Internet connectivity. During high Internet usage times (i.e., 11 a.m. to 1 p.m.), Internet connections were delayed and observations did not occur. In one school district, the cooperating SLP supervisor did not have a computer in the therapy room. To solve this issue, the cooperating SLP supervisor had to reserve and loan out a computer from the district technology coordinator. Finally, security issues forced an e-supervised graduate student to transport the equipment back and forth from her home at the end of the day. In all, the incorporation of technology into the supervisory process was believed to be somewhat burdensome whenever school districts did not have infrastructure to support its use.

\section{IMPACT ON SCHEDULING SUPERVISION}

\section{BENEFITS}

The use of e-supervision was associated with scheduling benefits. More specifically, graduate students believed it was easier for the ULE-Ss to allocate time in the day for supervision because no drive time was involved. An e-supervised graduate student stated, "It was convenient for the supervisor not to drive out to [the district]." Building off this theme, an in-person supervised graduate student believed long commutes to the school district negatively affected the frequency and quality of the university liaison supervision. This graduate student shared the following:

She only saw me for a short period of time. She would come and see me for a half hour or an hour once a month. Also, there was weather, or when our schedule would change, and I think it was about a 45 minute drive for her. So sometimes she would just say let's not do it today because l'm going to have to be in a meeting at this time and I'm not going to be able to make it there.

Next, videoconferencing technology allowed ULESs to multitask, which saved time in their schedules. When videoconferencing was used, ULE-Ss were able to observe and type out observation notes for graduate students, and these were emailed to students for consideration. In addition to the email correspondences, one e-supervised graduate student felt it was easier to schedule tele- and videoconferences with the ULE-S as opposed to in-person meetings.

\section{LIMITATIONS}

Whether or not ULSs had to drive to the school district, it was still difficult to coordinate schedules for observations and follow-up meetings. During the interviews, all four interviewees reported various problems related to scheduling, and these problems were not unique to ULE-Ss. When scheduling observations with ULE-Ss, graduate students experienced problems discussing feedback immediately after an observation, rescheduling cancelled observations that were due to student absences and "calamity days" (e.g., school closed because of a snow storm), and finding time to observe challenging children.

Similar scheduling conflicts were associated with inperson ULSs. One in-person supervised graduate student shared the following:

The only difficulties that we had were just scheduling conflicts. Maybe if they would continue with this in the future, maybe try and match up a supervisor who was closer to wherever you're located or centralize whoever they supervise in the same area, because I know she had people she was supervising up in Cleveland, and then she was in Akron, and then Wadsworth. So she was kind of all over the place. So I think it would be easier on them also. I don't know how they schedule that up, but that was the biggest problem with us...She was accessible by phone but it was hard to set it up. There were several times when we had to reschedule and cancel our meetings. I think that was just the hardest thing because she didn't live nearby and she was supervising other students. So it was hard to kind of schedule all that out with her schedule.

Upon reviewing the data, it appeared as though the in-person ULS experienced similar if not more scheduling problems, especially those related to excessive drive times. 


\section{SUPERVISOR QUALIFICATIONS}

Whenever a trained and experienced SLP ULS was unavailable, the College of Education assigned a school administrator or teacher. From the students' perspective, one criticism of university liaison supervision involved the use of non-SLP supervisors. One student shared the following:

There were some girls in my class who had someone who was either a principal or a special ed. teacher or somebody [as the liaison supervisor]. Which that is fine but they don't really know all the technical things that we're doing in speech so it's kind of hard to give a fair evaluation that way.

In-person supervised graduate students believed non-SLP ULSs did not understand the roles and responsibilities of a school-based SLP. An in-person supervised graduate student shared the following during the interview:

My ULS was actually a former high school principal and before that he was a physical education teacher so he did not know exactly the roles of SLPs so I had to explain that to him a little bit. He didn't know our job description. When we were initially speaking, he told me that he thought an SLP just dealt with lisps or not being able to pronounce an $/ r /$, and so I had to explain to him language, pragmatic skills, and he wasn't exactly sure what those were beforehand. So, I didn't really feel that he supervising me was entirely effective.

For this feasibility study, all e-supervised students were assigned state licensed and nationally certified SLPs as ULE-Ss. Interview data showed the e-supervised students appreciated having an SLP who acted as their ULE-S. One e-supervised graduate student shared the following about ULSs who were not SLPs: "[ULE-S] was better than the regular College of Education supervisor who was a principal. He didn't know about the field." The second e-supervised graduate student believed SLP ULSs were preferred because, "You still are getting feedback from an SLP at the university. The supervisor knows the 'speechier' things versus someone in the community who wouldn't know our field."

\section{GRADUATE STUDENT SUGGESTIONS FOR FUTURE E-SUPERVISION PROJECTS}

Graduate students provided suggestions for future e-supervision projects. It appeared as though advance planning and minor changes to the university liaison e-supervision process were needed. Three themes emerged during the interviews.

\section{TECHNOLOGY SUPPORT AND INFRASTRUCTURE}

Both e-supervised graduate students interviewed believed that adequate Internet connectivity, portable laptops, technology support, and buy-in from the school district were necessary in order for university liaison e-supervision to work effectively. Graduate students believed that more thought was needed prior to selecting student teaching sites where university liaison e-supervision was considered. One student justified this belief by saying, "A lot of schools aren't set up like the state-of-the-art university...they don't have the technology available." From the students' perspectives, not all school districts were appropriate sites for university liaison e-supervision. Graduate students further recommended that the school district administrator, cooperating SLP supervisor, and technology coordinator agree to e-supervision well in advance of student teaching practica.

In light of district technological limitations, both graduate students recommended that the districts and university coordinate and provide technology support. One graduate student provided the following reasoning: It is a pain when [technology support] isn't available. You needed the technology person to log in and set up your computer to the Internet and Ethernet each observation. You have to reserve a laptop one week in advance from the school district if a computer is not available.

Finally, it was recommended that the right technology and equipment should be available at the school site and stored there overnight. The graduate students did not want to "haul" the equipment or be responsible if something was stolen. It was further recommended that laptops were used for the following reasons:

Desktop computers aren't good for observing therapy. You can't move them so they are facing the therapy table. And if they are on the other side of the room, you can't see clearly what is going on at the table.

\section{CANDIDATES FOR UNIVERSITY LIAISON E-SUPERVISION}

Not only should potential school districts be selected carefully, but the skills and qualifications of the supervisor should also be considered. Graduate students believed future ULE-Ss should be comfortable and experienced with the videoconferencing technology and e-supervision. Next, ULE-Ss should have good social skills and be able to "develop interpersonal relationships through technology." Lastly, ULE-S should be SLPs with schoolbased experiences in settings that match the student teaching practicum site. During the interviews, a graduate student who was supervised by a former high school principal shared the following:

My only preference would be an actual SLP or at least an elementary school principal who may be a little more aware of the skills. By high school, that principal is not sitting in as many IEP meetings, and the speech [language] skills are a lot different then. So I just wish it was someone who had related experience that was actually supervising me. When you're there 3-4 days a week and then they don't know the skills that you're responsible for, I had to explain my goals. So when I actually gave him my lesson plans I had the technical goals and I had to write out in everyday parent-friendly jargon as to what they were. 
The data seemed clear; ULE-Ss should be selected carefully and their skills should match the purposes and design of the project.

\section{SCHEDULING CONSIDERATIONS}

The final theme that emerged pertained to scheduling considerations. Graduate students believed that it was important to establish the observation and meeting schedule in advance and conduct observations that were of adequate length and frequency. One e-supervised graduate student recommended that observations last for 30 minutes and occur once every 10 school days. The graduate student added that she did not feel university liaison e-supervision was needed more frequently or longer than that.

\section{DISCUSSION}

The study showed e-supervision supported graduate students in various ways during their student teaching practica. As was found in Watson (2003), e-supervision enabled graduate students to be placed and supervised in desirable school districts and paired with highly qualified SLP university supervisors. SLP graduate students showed a clear preference for ULSs who were SLPs with school-based experience. Wood, Miller, and Hargrove (2005) believed e-supervision provided graduate students with the opportunity to "experience the benefits of having supervision provided by masters and specialists with whom they might not otherwise have an opportunity to engage" (p.178). E-supervision was found to have removed barriers related to distance and shortages of qualified SLP supervisors.

In addition to providing a greater degree of access to supervisors and school districts, e-supervision enabled graduates students to develop clinical competency in the absence of in-person university liaison supervision. The technology ensured graduate students received adequate and specific supervision, feedback, and support from the ULE-Ss. Moreover, ULE-Ss and cooperating SLP supervisors had the ability to collaborate and connect the learning that occurred at the university and with the clinical application at the school districts.

As was found in Carlin et al. (2012) and Dudding and Justice (2004), e-supervision facilitated graduate students' feelings of independence and afforded them more control during the delivery of speech-language services. When ULE-Ss were used, graduate students felt more challenged and autonomous in their clinical decision-making skills. Graduate students also felt less threatened and overwhelmed when compared to past experiences with in-person supervision. Whether the graduate students "turned the screen off "or "forgot that they were being observed," they were able to focus on speech-language services and not on the supervisor. Similarly, Dudding (2004) found graduate students felt more at ease when e-supervision was used because the technology allowed the observation to be "less stressful and less intrusive than having the supervisor sitting in the room during the sessions" (p. 2).

While the data showed e-supervision benefited the supervisors and graduate students, it also positively affected the children and the climate of the therapy room. More specifically, children on the caseload were not distracted by ULE-Ss and small therapy rooms were not filled beyond capacity. The videoconferencing technology was flexible enough to be incorporated into therapy as a motivator for certain children on the caseload.

Scheduling issues equally impacted graduate students who were in-person and e-supervised. While it was difficult to find mutually convenient times for observations and follow-up meetings, e-supervision eliminated travel time. Gruenhagen, True, and McCracken (1999) argued that the time saved traveling to practicum sites could be used to provide supervision to graduate students. Furthermore, Watson (2003) believed supervisory sessions were more efficient because supervisors were no longer limited by strict schedules and lengthy commutes. Furthermore, graduate students recognized that mileage reimbursement was unnecessary. Dudding and Justice (2004) argued that the cost of the e-supervision technology and equipment was offset by the savings in ULE-Ss' time and travel expenses.

Finally, e-supervision was not without its disadvantages or challenges. As was found in Carlin et al. (2012), technological and equipment challenges appeared to be the greatest barrier during the e-supervision study. While time for travel was not needed, e-supervision required that time was set aside for reserving, installing, troubleshooting, and transporting technology and equipment. Time was also required to establish privacy policies and receive consent from parents and district administrators to permit e-supervision. Additionally, time was needed in order for ULE-Ss and cooperating SLP supervisors to establish rapport. Graduate students in the study believed the videoconferencing technology affected the relationship between the supervisors. The supervisor was also prevented from fully understanding characteristics and behaviors of the children. Furthermore, the technology prevented the ULE-S from making recommendations related to the physical space and observing during classroom-based services. 


\section{CONCLUSION}

While e-supervision was not without its weaknesses, positive outcomes and graduate student perceptions emerged. Most notably, graduate students believed they were adequately supervised and supported by the ULE-Ss. In addition, graduate students were comfortable during observations and felt independent and in control of the therapy sessions.

The incorporation of videoconferencing reduced supervisor travel time and expenses, eased scheduling conflicts, and allowed multiple graduate students to be supported in desirable school districts. E-supervision connected highly qualified SLP supervisors with desirable clinical placements that would not otherwise be available to graduate students. At these placements, graduate students not only developed diverse clinical skills, but the children on the caseload were not distracted by the observing ULSs.

Looking to the future, strategies need to be implemented to reduce supervisory isolation, increase stakeholder rapport, and broaden the settings where observations occur. Additionally, technological limitations should be addressed. Several implications for future practice were identified.

\section{IMPLICATIONS FOR PRACTICE}

In light of the benefits that were associated with university liaison e-supervision, universities and school districts are encouraged to consider the following implications for practice. First, school district administrators, technology staff, cooperating SLP supervisors, and parents should agree in advance to implement e-supervision. School district technology policies vary and buildings might not be equipped to support e-supervision. Additionally, the culture of the school district and building might preclude the use of e-supervision, whether due to misperceptions, negative experiences, restrictive policies, or other concerns.

Second, the right SLP supervisor should be selected. ULE-Ss should be SLPs with supervisory and schoolbased experiences. The results of the study clearly showed graduate students in speech-language pathology programs preferred highly qualified SLP supervisors over principals and teachers. During a time when graduate students develop speech-language clinical competency, ULE-Ss need to possess school-based experiences that match the student teaching site.

Third, technology support personnel were critical players in the implementation of successful e-supervision projects. As was found in previous research, graduate students believed professional development and ongoing technological support were needed at the beginning and throughout the e-supervision project (Brandoff \& Lombardi, 2012; Conn, Roberts, \& Powell, 2009). Once the ULE-Ss, cooperating SLP supervisors, and graduate students were trained, technology staff could remove firewalls, install the videoconferencing technology and equipment (e.g., webcams), and troubleshoot and resolve problems.

Next, trial runs should be conducted in advance to identify any glitches in the technology and equipment and test Internet connectivity. During the trial runs, the physical space (e.g., therapy table, chairs) could be configured in such a way as to ensure target children were seen and heard by the e-supervisor. The ULE-Ss, cooperating SLP supervisors, and graduate students could also determine a protocol for interrupting therapy sessions and how best to use the instant messaging feature.

Finally, it appeared as though ULE-Ss, cooperating SLP supervisors, and graduate students should hold in-person meetings prior to the start of student teaching practica. Conn et al. (2009) and Carlin et al. (2012) claimed these initial in-person meetings were necessary to establish rapport and ensure all parties interacted positively and appropriately. The data from the present study further confirmed that rapport building was critical at the onset of the project. At this in-person meeting, criteria could be set related to timelines, appointments, cancellations, roles, and ULE-S-child interactions.

\section{LIMITATIONS OF THE STUDY}

While promising results were found, several limitations impacted the study and affected the generalizability of results. First, the sample size was small and pulled from a narrow demographic area. Future research should sample a larger number of participants from various socioeconomic and geographic areas. Second, ULE-Ss only observed graduates students during pullout services to children with milder disabilities. Research should investigate whether the benefits of e-supervision were maintained across educational settings and disabilities. Next, SLP e-supervisors were compared to non-SLP inperson supervisors. It was not clear if it was e-supervision or the use of non-SLP ULSs that impacted graduate students' perceptions. Future studies should only use SLP supervisors to determine if e-supervision was comparable to in-person university liaison supervision. Last, followup interviews were not conducted, which prevented the researchers from gaining additional information to clarify survey responses. Additional research was needed in order to understand the differences between in-person and e-supervisors on topics related to diversity, ethics, appointments, and consultation. 


\section{REFERENCES}

1. American Speech-Language-Hearing Association. (February, 2007). The Subject is Change: Creating a Vision for the Future Education of Speech-Language Pathologists. Presentation made at the 2007 SpeechLanguage Pathology Education Summit, New Orleans, Louisiana.

2. American Speech-Language Hearing Association. (2008). Clinical Supervision in Speech-Language Pathology [Technical Report]. Available from www.asha.org/policy.

3. Brandoff, R. \& Lombardi, R. (2012). Miles apart: Two art therapists' experiences of distance supervision. Art Therapy: Journal of the American Art Therapy Association, 29(2), 93-96.

4. Carlin, C. H., Carlin, E.L., Milam, J. L., \& Weinberg, T. (2013). E-supervision \& e-mentoring: Prof e s s i o n a I development for current and future professionals. In K. Todd Houston. Telepractice in speech-language pathology. Plural Publishing, Inc.

5. Carlin, C. H., Milam, J. L., Carlin, E. L., \& Owen, A. (2012). Promising practices in e- supervis ion: Exploring graduate speech-language pathology interns' perceptions. International Journal of Telerehabilitation. 4(2), 25-37.

6. Conn, S.R., Roberts, R.L., \& Powell, B.M. (2009). Attitudes and satisfaction with a hybrid model of counseling supervision. Educational Technology \& Society, 12, 298306.

7. Dudding, C. C. (2004) Perceptions of the use of videoconferencing for supervision: Differences among graduate clinicians. Unpublished doctoral dissertation, University of Virginia, Charlottesville.

8. Dudding, C. C. (2009). Digital videoconferencing applications across disciplines.Communication Disorders Quarterly, 30, 178-182.

9. Dudding, C. C. \& Justice, L. M. (2004). An e-supervision model: Videoconferencing as a clinical training tool. Communication Disorders Quarterly, 25, 145-151.

10. Flick, U. (2004). Triangulation in qualitative research. In U. Flick, E. von Kardorff, \& I Steinke. A Companion to Qualitative Research. London: Sage.

11. Gruenhagen, K., True, J., \& McCracken, T. (1999). Using distance education technologies for the supervision of student teachers in remote rural. Rural Special Education Quarterly, 18(3/4), 58-65.

12. Hallett, T. L. (2002). The impact of technology on teaching, clinical practice, and research. The ASHA Leader, 7(11), 4.

13. Johnson, R. B., Onwuegbuzie, A. J., \& Turner, L. A. (2007). Toward a definition of mixed methods research. Journal of Mixed Methods Research, 1, 112-133.

14. Merriam, S. B. (1998). Qualitative research and case study applications in education: Revised and expanded from case study research in education. Jossey-Bass, CA: San Francisco.

15. Olson, M. M., Russell, C. S., \& White, M. B. (2001). Technological implications for clinical supervision and practice, The Clinical Supervisor, 20, 201-215.

16. Robinson, T., Creaghead, C., Hooper, C., Watson, J., \& McNeilly, L. (2007). Speech-language pathology Education Summit proceedings. Rockville, MD: American Speech-Language-Hearing Association.
17. Watson, J. C. (2003). Implementing computer technology into the delivery of counseling supervision. Journal of Technology in Supervision, 3(1).

18. Wood, J. A., Miller, T. W., \& Hargrove, D.S. (2005). Clinical supervision in rural settings: A telehealth model. Professional Psychology: Research and Practice, 36, 173-179.

19. Yusko, B. P. (2004). Caring communities as tools for learnercentered supervision. Teacher Education Quarterly, 31(3), 53-72. 


\section{APPENDIX}

\section{GRADUATE STUDENT INTERVIEW QUESTIONS: E-SUPERVISION}

1. Thinking back to your student teaching experience, please tell me about your experiences with university liaison e-supervision.

2. Do you feel this method allowed you to be adequately supervised? Why or why not?

3. What do you think are the strengths and weaknesses of university liaison e-supervision?

4. If you could do it over, would you be willing to be e-supervised again? Why or why not?

5. With regard to university liaison e-supervision, what do you think should be done the same in the future?

6. With regard to university liaison e-supervision, what do you think should be done differently in the future?

7. When you think back to other face-to-face supervision experiences you had, how was university liaison e-supervision the same? How was it different?

8. Is there anything else you would like to share about your experiences with university liaison e-supervision?

\section{GRADUATE STUDENT INTERVIEW QUESTIONS: \\ FACE-TO-FACE SUPERVISION}

1. Thinking back to your student teaching experience, please tell me about your experiences with university liaison supervision.

2. Do you feel this method allowed you do be adequately supervised? Why or why not?

3. What do you think are the strengths and weaknesses of face-to-face university liaison supervision?

4. If you could do it over, would you be willing to receive the same type of university liaison supervision again? Why or why not?

5. With regard to university liaison supervision, what do you think should be done the same in the future?

6. With regard to university liaison supervision, what do you think should be done differently in the future?

7. When you think back to other face-to-face supervision experiences you had, how was university liaison supervision the same? How was it different?

8. Is there anything else you would like to share about your experiences with university liaison supervision? 
